\title{
LA VIVENCIA DEL TIEMPO EN ANTONIO MACHADO
}

\section{Armando LÓPEZ CASTRO}

\author{
Universidad deLeón
}

El hombre ha caído del tiempo paradisíaco y se ve diferente en la historia. Sin embargo, aunque esté alejado de él, ocupa el centro de su conciencia, pues el tiempo no está hecho para ser conocido, sino para ser vivido. Mientras la conciencia implica distancia, un sentimiento de autonomía que sólo tiene un valor subjetivo, la vivencia es un ser cualitativo y se caracteriza por su inmediatez objetiva ("Todo aquello que llega con tal inmediatez a mi yo que entra a formar parte de él es una vivencia", escribe Ortega en 1913, siguiendo a Dilthey). EI tiempo constituye nuestro elemento vital. De las dos concepciones clásicas del tiempo, la temporal hebrea y la intemporal griega, esta última fue incorporada por la espiritualidad cristiana, ya que el Espíritu en sí mismo es intemporal, eterno. La noción de que el alma, y no los cuerpos, es la verdadera medida del tiempo subyace en la doctrina de Plotino, para quien el tiempo es una "categoría íntima", y se prolonga en el pensamiento de San Agustín, donde el tiempo aparece como realidad vivida. En la edad moderna, la concepción absolutista de Newton y la relacionista de Leibnitz son asimiladas por Kant, que concibe el tiempo como una concepción apriorística. La gran aportación de la cultura romántica fue el descubrimiento del individuo. La insistencia en lo temporal y lo histórico se plasma en la filosofía de Bergson, cuyo método intuitivo intenta penetrar la realidad y extraer de ella, por medio de imágenes, lo que los conceptos son incapaces de revelar, visible en el contraste machadiano entre razón e intuición, y en la filosofía de Dilthey, donde la conciencia trascendental se resuelve en conciencia histórica. Dentro del temporalismo contemporáneo, el idealismo fenomenológico de Husserl, que concibe el tiempo como la forma unitaria de las vivencias en el flujo de lo vivido, y el existencialismo del primer Heidegger, representado por Ser y Tiempo y la conferencia sobre qué es metafísica, donde el tiempo se concibe a partir de la muerte, constituyen dos referencias ineludibles en el pensamiento de Machado. En sus escritos, el tiempo es un aspecto de la heterogeneidad propia del alma, una consecuencia de su honda soledad ${ }^{1}$.

Dentro de la historia literaria hispánica, el modernismo se presenta como un movimiento de rebeldía frente al positivismo burgués, afirmando el espíritu individual del artista y desarrollando las potencias irracionales: el sentimiento, la memoria y la imaginación. El irracionalismo conlleva el alejamiento de toda generalización, elevando a primer término la concepción temporalista de la vida

${ }^{1}$ En cuanto a los sentimientos, que son a la vez temporales y espaciales, véase el estudio de C. Gurméndez, Teoría de los sentimientos, México (FCE) 1984, pp.147-159. Sobre la temporalidad en los poemas de Machado, tengo en cuenta, entre otros, el trabajo de A. Sánchez Barbudo, Estudios sobre Galdós, Unamuno y Machado, $3^{\mathrm{a}}$ ed., Barcelona (Lumen) 1981, pp.388-397. 
humana. El tiempo deja de ser una categoría abstracta para convertirse en percepción subjetiva e interiorizada. De las dos versiones del mundo que nos ofrece el poeta moderno, la analógica basada en la armonía y la irónica basada en la diferencia, la superación poética del tiempo lineal de la Historia por el tiempo cíclico de la Naturaleza es clave de la poesía modernista, dispuesta a satisfacer sus ideales absolutos mediante el culto a la Belleza. En Machado, la conciencia existencial del tiempo destructor en el presente es lo que le lleva a reconstruir el pasado con la esperanza de un futuro mejor, según vemos en este simbólico y enigmático poema:

Me dijo un alba de la primavera:

Yo florecí en tu corazón sombrío

que no cortas las flores del camino.

5 Tu corazón de sombra, ¿acaso guarda

el viejo aroma de mis viejos lirios?

¿Perfuman aún mis rosas la alba frente

del hada de tu sueño adamantino?

Respondí a la mañana

10 Sólo tienen cristal los sueños míos.

Yo no conozco el hada de mis sueños

ni sé si está mi corazón florido.

Pero si aguardas la mañana pura

que ha de romper el vaso cristalino,

15 quizás el hada te dará tus rosas,

mi corazón tus lirios.

El diálogo del hablante con una mañana primaveral, similar al que mantie ne con la noche en el poema XVI, donde se da idéntico desdoblamiento de su personalidad, revela una renovación de las viejas ilusiones gracias al poder del sueño creador. Consciente de lo efímero ("caminante viejo / que no cortas las flores del camino"), el yo poético lamenta que la memoria no guarde los recuerdos de esa lejana juventud ("sólo tienen cristal los sueños míos") y espera que esos recuerdos renazcan en el futuro ("Pero si aguardas"). En virtud del sueño creador, donde memoria vital e imaginación poética se funden y en donde se engastan los distintos recursos expresivos, tales como la insistencia del adjetivo viejo, con su continuidad temporal; el val or temporal de las formas verbales ("ha muchos años") y los adverbios ("aún"); la resonancia modernista del hada rubeniana, asociada al "sueño adamantino" de la niñez; el florecimiento de la naturaleza como signo de renovación primaveral; y la serie de símbolos encadenados ("corazón sombrío", "flores del camino", "Ios viejos lirios", "Ias rosas", "el cris- 
tal”, “la mañana pura” y "el vaso cristalino"), el poeta logra anular la angustia del tiempo lineal e instalarse en la vitalidad primaveral del tiempo cíclico².

En el barroco español, la vivencia del tiempo suele ir unida a la de la muerte, que es siempre lo otro real, lo otro en lo cual somos. Para Quevedo, vivir es ir muriendo, de manera que el tiempo es sólo y todo muerte. El ser vive inmerso en lo efímero, en el tiempo de un cansancio existencial ("soy un fue, y un será, y un es cansado"). El lenguaje poético de Machado, lleno de signos temporales, emerge frente a la caducidad y sueña conjurar la muerte. La caducidad es el ser. Es sólo la experiencia de la escritura, donde vida y muerte aparecen como espejos de una misma realidad, la que retiene la fugacidad incesante y deja ver algo no dicho, pero latente, la inminencia de la muerte desde la vida todavía por vivir. En el poema XXXV de Soledades (1907), compuesto de un solo alejandrino, hay una meditación sobre la inevitabilidad de la muerte en medio de la vida. Diceasí:

\section{Al borde del sendero un día nos sentamos. Ya nuestra vida es tiempo, y nuestra sola cuita son las desesperantes posturas que tomamos para aguardar... Mas Ella no faltará a la cita.}

Al oír estos versos, resulta inevitable relacionarlos con la teoría heideggeriana de la angustia, que arranca de nuestra existencia mortal. Es posible que Machado conociera la traducción de ¿Qué es metafísica?, publicada en Cruz y Raya en septiembre de 1933, e incluso que empezara a leer Sein und Zeit (1927) en el original alemán, hasta que después publicó Gallimard la versión francesa de algunos capítulos en 1937, pero a la al tura de Soledades (1899-1907), el pensamiento del filósofo de Friburgo no era conocido, pues su primera obra Nuevas indagaciones sobre la lógica data de 1912, por lo que hay que pensar en la crisis espiritual del positivismo burgués, de la que arranca a su vez la crisis existencial y temporal del hombre en el siglo XX. En este sentido, habría que remontarse hasta el escrito en prosa de Bécquer, "Pensamientos", fechado en 1862, en donde leemos: "Así pasan los años, y me encuentran y me dejan sentado al borde del camino de la vida... jsiempre esperando!". Aunque el poeta romántico aguarda "a una mujer que no llega nunca", lo importante es la percepción del tiempo desde la conciencia individual y existencial del poeta. En el breve espacio del poema, "el sendero" como símbolo de la vida humana, la angustia de la espera ("sola cuita"), re forzada por la sugerencia de los puntos suspensivos, y la presencia velada de la muerte ("Ella"), confluyen en una radicalización de la temporalidad de la exis-

\footnotetext{
${ }^{2}$ Un análisis más detenido de este poema puede verse en el estudio de Ramón de Zubiría, $L a$ poesía de Antonio Machado, Madrid (Gredos) 1973, pp.26-28. Sobre el conflicto entre el tiempo lineal, el de la Historia, y el tiempo cíclico, el de la Poesía, véase el ensayo de Carlos Javier Morales, "Dos versiones del modernismo: la conciencia del tiempo en Rubén Darío y Antonio Machado", Revista de Literatura, LXII, 123 (2000), pp.107-131.
} 
tencia ("Ya nuestra vida es tiempo"), de la vida del hombre como ser en el tiempo. Esta conciencia de la finitud, asentada no en el espacio que divide, sino en el tiempo que une, alumbra una semilla de esperanza a pesar de la desesperanza ("Ias desesperantes posturas que tomamos"), pues la esperanza se funda en la trascendencia y anticipa lo que todavía no ha sido, lo nuevo posible3.

Si comparamos la primera edición de Campos de Castilla (1912), publicada por la Editorial Renacimiento, dirigida entonces por Gregorio Martínez Sierra, con la segunda, incorporada a las Poesías completas (1917) y aparecida en las Ediciones de la Residencia de Estudiantes, observamos una mayor amplitud y variedad de líneas temáticas y formales en la segunda, a las que contribuyen experiencias tan decisivas como la muerte de Leonor, la meditación filosófica y religiosa de los años de Baeza, y la preocupación comunitaria, intensificada a raíz de la muerte de Francisco Giner de los Ríos en 1915. En esos años de madurez, el período que va de 1912 a 1916, es cuando se produce el paso de la esencial "homogeneidad del yo" a la esencial "heterogeneidad del ser", una nueva expresión poética de la "sentimentalidad colectiva", presentada de forma más aforística y menos afectiva. Este cambio de escritura no hace más que reflejar un cambio de mentalidad. En lo que al tiempo se refiere, es muy distinta la actitud que muestra el poeta en "A un olmo seco", condicionada por la inminente muerte de Leonor, a la que ofrece en "A Narciso Alonso Cortés, poeta de Castilla", donde el grado de emoción temporal en la creación poética anticipa al gunas de las reflexiones estéticas en prosa. Entre ambos extremos, los "Proverbios y cantares", a los que Pedro Salinas Ilamó acertadamente "cantares de pensador", Ilenos de lirismo cordial y entre los que destaca el cantar XXIX, admirable por su condensación y expresividad

\author{
Caminante, son tus huellas \\ el camino, y nada más; \\ caminante, no hay camino, \\ se hace camino al andar. \\ $5 \mathrm{Al}$ andar se hace camino, \\ $y$ al volver la vista atrás \\ se ve la senda que nunca \\ se ha de volver a pisar. \\ Caminante, no hay camino, \\ 10 sino estelas en la mar.
}

\footnotetext{
${ }^{3}$ Refiriéndose a este poema, señala J.L. Aranguren: "No creo que haya en la historia universal de la poesía una anticipación poética tan clara y terminante, en sólo cuatro versos, del sentimiento de la vida subyacente a esa filosofía actual de la finitud temporal, del cuidado, de la desesperación (no gesticulante y retórica, a lo Unamuno, sino mansa y callada) y el ser-para-la-muerte, como la que se expresa aquí", en su artículo "Esperanza y desesperanza de Dios en la experiencia de la vida de Antonio Machado", Cuadernos Hispanoamericanos 11-12, 1949, 383-397. En cuanto a la muerte como inminencia de la vida, véase el ensayo de J. Cano Ballesta, "Antonio Machado y la crisis del hombre moderno", en Estudios sobre Antonio Machado (ed.), José Ángeles, Barcelona (Ariel) 1977, pp.73-96.
} 
La modernidad es el tiempo de las formas breves, de los libros de fragmentos, como los de Nietzsche o Bergamín. El carácter sintético del aforismo y la sentencia se ajusta a la forma asistemática de ejercer el pensamiento, sobre todo el poético, que procede de lo hondo y tiende a la concentración. Construido sobre la metáfora del río heraclitano, según la cual no volvemos a bañarnos dos veces en el mismo río, este poema muestra una inquietud existencial, dada por el carácter irreversible que da el tiempo a nuestra vida. Sin embargo, frente a la filosofía del absurdo, donde el hombre aparece arrojado a un mundo sin caminos, lo que aquí se afirma es el valor moral de nuestros actos, pues la vida no se nos da hecha, sino que tenemos que hacerla ("no hay", pero "se hace"). De ahí que la alternancia de subjetividad y objetividad confluyan en los dos últimos versos, donde cesa el diálogo y queda sólo la pura duración. El dominio del flujo temporal en la línea de Heráclito y Bergson, visible en el dinamismo de la apelación ("caminante"), en las construcciones con infinitivo ("al andar", "al volver") y el adverbio "nunca", y en los símbolos del "camino" y el "mar", reveladores de que el hombre no tiene destino o no lo conoce, refleja el tránsito inevitable de la vida, en la que el hombre va cumpliendo un itinerario existencial. Por eso, la contradicción resuelta en los versos finales se prolonga en el cantar XLIV (“Todo pasa y todo queda; / pero lo nuestro es pasar, / pasar haciendo caminos, / caminos sobre la mar"), donde la fusión de transitoriedad y supervivencia revela que no todo es fatalidad, sino que hay un camino abierto a la esperanza4.

Hay dos versos machadianos que perduran con especial intensidad en la memoria del lector: El primero ("Hoy es siempre todavía") forma parte de la sección "Proverbios y cantares", de Nuevas canciones (1917-1930), obra de sus años de madurez y en la que asistimos a un proceso de esencialización de la palabra poética. El segundo ("Estos días azules y este sol de la infancia"), escrito a lápiz en un papel y encontrado por su hermano José en uno de los bolsillos de su gabán, concentra, en su brevedad extrema, el tiempo de la infancia y el del exilio, la virtualidad de toda una vida. Desde el punto de vista artístico, tal vez sea más importante el primero, pues el instante del tiempo estético, donde tiene lugar el sentimiento de la presencia naciente de lo real, permite captar el sentido más profundo de la temporalidad: “H oy es siempre todavía” (poema VIII).

El tiempo sólo tiene una realidad, la del instante. Si en el poema LVII de Soledades (1907) el poeta decía “ ¡A yer es Nunca jamás!”, ahora, en Nuevas canciones, afirma "Hoy es siempre todavía". En realidad, el paralelismo de los versos, dos adverbios de tiempo, el mismo verbo copulativo y sendas parejas de adverbios negativos y afirmativos, nos hace ver que son complementarios, pues la irrealidad del instante creador, al prolongar ("todavía") lo temporal ("Hoy") en lo in-

${ }^{4}$ La resonancia bergsoniana de la pura subjetividad fluyente, lo que Bergson llama la "pura heterogeneidad" de lo psíquico, ha sido estudiada por E. Frutos en su trabajo Creación poética, Madrid (Porrúa Turanzas) 1976, pp.151-215. En cuanto al poema, uno de sus mejores análisis es el que nos ofrece M. Mayoral, Poesía española contemporánea, Madrid (Gredos) 1973, pp.98-108. 
temporal ("siempre"), pone a prueba la realidad entera. Todo lo que es durable es el don de un instante, cuya síntesis de pasado y futuro le da un carácter absoluto5.

Durante la composición de Nuevas canciones (1917-1930), no sólo se da el 'salto al otro' como superación del idealismo, sino también una relación constante entre la poesía y la filosofía, entre la experiencia poética y los comentarios en prosa, pues toda reflexión filosófica tiene sus raíces en la intuición poética. Dado que para Machado su obra en verso y en prosa constituyen dos vías de acceso a una misma visión de la realidad, las interferencias entre poesía y pensamiento serán constantes en su escritura, si bien, a partir de los años de Baeza, la síntesis expresiva del estilo aforístico le permitirá tratar mejor sus temas esenciales y acercarse al pensamiento poético, que exige multiplicidad de formas y pluralidad de personas en quien darse. Y así los poemas de Nuevas canciones, sobre todo los de la serie "De mi cartera", donde tan hábilmente se unen el sentido crítico y la intención creadora, no se entenderían sin este sentir propio del pensamiento único que los habita, que por darse en la intimidad del ser, se hará universal y trascendente. Un ejemplo de este pensamiento, que nace entero y configura al hombre mismo, lo tendríamos en el poema "Olivo del camino", que abre Nuevas canciones ("Olivo solitario, / lejos del olivar, junto a la fuente, / olivo hospitalario / que das tu sombra a un hombre pensativo / y a un agua transparente"), donde el que medita, el hombre pensativo, no está solo, sino al borde del camino por donde pasan los hombres, los otros de sí mismo. Y así la unidad indestructible del pensamiento machadiano se muestra en el arranque común de poesía y filosofía, en la revelación de la palabra como fluir temporal, expuesta en tres versos, de los que sacó más tarde, por reflexión y análisis, toda su teoría poética. Recordémoslos una vez más: “Ni mármol duro y eterno, / ni música ni pintura, / sino palabra en el tiempo".

A demás de aludir al diálogo necesario entre las distintas artes, muy del siglo XIX, donde la música y la poesía lírica fueron exaltadas por encima de las artes plásticas, el lenguaje de este poema, con su triple negación de la frialdad formal parnasiana, la música simbolista de Verlaine y la pintura impresionista, lo que hace es concentrar la atención del lector en el verso final ("sino palabra en el tiempo"), pues si se niega algo es para afirmar la posibilidad de otra cosa. Hay

${ }^{5}$ Aludiendo a la síntesis realizada por el instante poético, G. Bachelard dice: "La poesía es una metafísica instantánea. En un breve poema, debe dar una visión del universo y el secreto de un alma, un ser y unos objetos, todo al mismo tiempo. Si sigue simplemente el tiempo de la vida, sólo puede ser más que la vida inmovilizando la vida, viviendo en el lugar de los hechos la dialéctica de las dichas y las penas. Y entonces es principio de una simultaneidad esencial en que el ser disperso, en que el ser más desunido conquista su unidad", en La intuición del instante, México (FCE) 1987, p.89. Sobre la captación instantánea del tiempo machadiano, tiempo cualitativo sólo perceptible intuitivamente, Cf. J. López Morillas, "Antonio Machado y la interpretación temporal de la poesía", en Intelectuales y espirituales, Madrid (Revista de Occidente) 1961. Recogido en Antonio Machado, (eds.), R. Gullón y A.W. Phillips, Madrid (Taurus) 1973, pp.251-266. 
en tales versos una gran condensación de materia poética, por lo que es necesario acudir a los comentarios en prosa para apreciar todo su alcance. En una nota del cuaderno Los complementarios (1912-1926), fechado en Segovia el 1 de agosto de 1924 y contemporánea, por tanto, de la escritura de Nuevas canciones, nos dice Machado: "Es evidente que la obra de arte aspira a un presente ideal, es decir, a lo intemporal. Pero esto de ninguna manera quiere decir que pueda excluirse el sentimiento de lo temporal en el arte. La lírica, por ejemplo, sin renunciar a su pretensión a lo intemporal, debe darnos la sensación estética del fluir del tiempo, es precisamente el flujo del tiempo, uno de los motivos líricos, que la poesía trata de salvar del tiempo, que la poesía pretende intemporalizar". La obra de arte, en tanto que portadora de un contenido posible, tiene que ser realizada fuera de sí, de ahí que su interior sea una tensión hacia un contenido ideal que ha de revelarse. Pero, además de esta tensión ideal-real, la forma debe insertarse en el vivir ("darnos la sensación estética del fluir del tiempo"), pues sólo en esa mediación de la forma en la vida, afirmando el momento irracional y vivo, lo poético se constituye como proceso y muestra su significado en la fluidez de la forma musical. Lo que Machado pretende expresar con "el fluir del tiempo", con la fluidez de lo formal, es una realización intermediadora de lo poéticotrascendental, sus condiciones de posibilidad.

Tan sólo unos años más tarde, en "El arte poético de Juan de Mairena", recogido en la edición de Poesías completas (1928), encontramos una variante del texto anterior en boca del profesor apócrifo: “Todas las artes aspiran a productos permanentes, en realidad, a frutos intemporales. Las llamadas artes del tiempo, como la música y la poesía, no son excepción. El poeta pretende, en efecto, que su obra trascienda de los momentos psíquicos en que es producida. Pero no olvidemos que, precisamente, es el tiempo (el tiempo vital del poeta con su propia vibración) lo que el poeta pretende intemporalizar, digámoslo con toda pompa: eternizar. El poema que no tenga muy marcado el acento temporal estará más cerca de la lógica que de la lírica". La ruptura lingüística, propia del paréntesis, sirve para matizar la experiencia interior como espacio constituyente de lo artístico, la naturaleza intermedia de la palabra poética, en tanto que posibilidad de lo absolutamente otro, de modo que tiempo y eternidad se funden en el fluir de la palabra poética. En síntesis, lo que la canción pone de relieve, con sus complementarios textos en prosa, es el impulso esclarecedor de la palabra poética, palabra que aspira a trascender el lenguaje para llevarnos al silencio, fondo último de toda escritura6.

\footnotetext{
'Para Machado, la poesía es el arte de "poner la palabra en el tiempo", y este tiempo tiene muy poco que ver con el cronológico, sino que es un tiempo interior, anímico, un tiempo de conciencia. Este tiempo ha sido analizado por M. Scorsoni en su estudio, "El concepto de tiempo vital" en La poética de Antonio Machado, University of Siracuse, 1968. En cuanto a la teoría poética contenida en la serie "De mi cartera", Cf. el artículo de Aurora de Albornoz, "Antonio Machado: De mi cartera. Teoría y creación”, Cuadernos Hispanoamericanos 304-307, Vol.II, pp.1014-1028.
} 
Más que un tema determinado, el tiempo es el aire que respira la poesía occidental del siglo XX. Nadie ha sabido mejor que Heidegger captar la angustia temporalista que predomina en el pensamiento europeo después de la primera guerra mundial. A partir de entonces, el hombre aparece como ser caído del tiempo, traicionado por la historia, cuyo primer ejemplo es Job. Frente a la oquedad del tiempo histórico, está la lucha y el dolor del poeta. Pocos poetas tan imbuidos de lo temporal como Machado, en cuya escritura laten siempre dos preocupaciones complementarias: la obsesión por el paso del tiempo y la conciencia de que, en la disolución a la que él nos somete, sólo la palabra puede garantizar la victoria sobre la muerte y el olvido. La palabra poética se propone salvar del fluir del tiempo las cosas que se precipitan hacia la muerte, fijándolas en la intemporalidad del instante. Por eso, su poesía aparece llena de preguntas sobre el tiempo y sus mejores poemas muestran un contexto dramático que re fleja la difícil prueba de acotar la transitoriedad desde el discurso mismo transitorio. La búsqueda de la conciencia simultánea del fluir temporal, con la que se pretende unificar el pasado, el presente y el futuro, aparece ya en los poemas de Soledades, llenos de fuentes, jardines olvidados y cantos de los niños, elementos simbólicos que sugieren un "sentimiento del tiempo", y no deja de prolongarse hasta sus últimas canciones, como la dirigida a Guiomar ("Y te enviaré mi canción: / Se canta lo que se pierde, / con un papagayo verde / que la diga en tu balcón"), en la que se canta el fluir del tiempo, lo que fue, es y será por medio de la palabra. Entre ambos extremos y como límite o punto de coincidencia entre poesía y filosofía, los textos aforísticos de Nuevas canciones y, tras ellos, las "Canciones a Guiomar", algunas de las composiciones finales de A bel Martín, sobre todo las tituladas "Últimas lamentaciones de A bel Martín", "Muerte de A bel Martín" y "Otro clima”, y algún poema escrito durante la guerra. Entre las primeras, habría que destacar esta levey nostál gica canción:

No sabía

si era un limón amarillo

lo que tu mano tenía,

o el hilo de un claro día,

5 Guiomar, en dorado ovillo.

Tu boca me sonreía.

Yo pregunté: ¿Qué me ofreces?

¿Tiempo en fruto, que tu mano eligió entre madureces

10 de tu huerta?
¿Tiempo vano

de una bella tarde yerta?

¿Dorada ausencia encantada?

¿Copia en el agua dormida?

15 ¿De monte en monte encendida, la alborada verdadera?

¿Rompe en sus turbios espejos amor la devanadera

20 de sus crepúsculos viejos?

La relación amorosa de Machado con Guiomar, segundo gran amor en la existencia del poeta sevillano, comienza en los años de Segovia, entre 1927 y 1928, y se prolonga en los últimos diez años de su vida. En las Canciones dedicadas a Guiomar, donde el olvido es el punto de partida para la recreación imaginativa de la amada, el poeta siente al fin que se realizan sus sueños: la sustitu- 
ción del viejo amor por el verdadero, que llega colmando el tiempo. La ambigüedad en que transcurre la composición, subrayada por la forma verbal que abre el poema ("No sabía"); la inquietud de las preguntas sin respuesta, salvo los dos últimos tercetos, que sugieren una certeza esperanzada; la serie de contrastes entre el tiempo de las plenitudes ("tiempo en fruto") y el tiempo efímero ("Tiempo vano"), lo yerto y lo dorado, "la al borada" y los "crepúsculos"; y la serie de imágenes y símbolos habituales en el léxico del poeta ("tarde yerta", "agua dormida", "turbios espejos", "crepúsculos viejos"), destacando el fuego ("De monte en monte encendida"), como símbolo de transformación amorosa, ofrece una escritura en tensión, consustancial al asombro del amante deslumbrado, donde la ambivalencia persiste, pues no se sabe si es limón o luz lo que hay en esa mano, y la alternancia no deja de estar presente, ya que no sabemos si el amor es auténtico y durable o superficial y pasajero. Con todo, resulta evidente que Guiomar tiene que ver con la tarde dorada en que esperó el amor ("dorada ausencia encantada"), con el deseo engendrado por la ausencia amorosa más que con la privación del vacío y la muerte, de modo que "el hilo de un claro día" vendría a simbolizar la iniciación de un tiempo de amor, un amor nuevo que viene a romper esa madeja ("devanadera") de antiguas tristezas, de "crepúsculos viejos", en la atemporalidad del sueño. El tránsito del amor real al soñado, ámbito de tensión entre las zonas de sombra y la pura luminosidad, deja aparecer algo real con carácter de absoluto. Bajo la temporalidad del sueño, el amor despliega su acción trascendente?.

La zozobra de andar por los tiempos múltiples, esas capas de ser que forman la trama de la vida humana y nos envuelven desde la infancia, engendra el deseo de librarse de la sucesión, de vivir el instante de la muerte, donde el ser se ve enteramente a sí mismo. Un buen ejemplo de ello es el poema "Últimas lamentaciones de A bel Martín", donde la existencia se temporaliza en el instante del tiempo estético, donde el yo restaura el latido del ser, y la palabra penetra en el latido del silencio. De ese instante consumado y fingido, tiempo inmemorial que ronda la atemporal idad, entresacamos los siguientes versos:

\author{
La ausencia y la distancia \\ volví a soñar con túnicas de aurora; \\ firme en el arco tenso la saeta \\ del mañana, la vista aterradora \\ de la llama prendida en la espoleta \\ de su granada.
}

\footnotetext{
${ }^{7}$ Refiriéndose a la ambigüedad de este poema, señala B. Sesé: "Todo este poema, donde el deslumbramiento de la dicha alterna con un sentimiento difuso de irrealidad y de ilusión, deja una impresión equívoca de éxtasis fugaz y de desencanto, de alegría plena, promesa de nueva dicha, y de nostalgia desolada", en Antonio Machado (1875-1939), Madrid (Gredos) 1980, Vol.II, p.560. En cuanto al amor como tiempo compartido, véase el análisis de Leopoldo de Luis, Antonio Machado. Ejemplo y lección, Madrid (Fundación Banco Exterior) 1988, p.155.
} 


\section{¡Oh Tiempo, oh Todavía \\ preñado de inminencias! \\ tú me acompañas en la senda fría, \\ tejedor de esperanzas e impaciencias.}

Este poema, que apareció por vez primera en 1933, es al mismo tiempo una evocación de la infancia lejana y una expectación ante el futuro. La memoria, re velación ineludible de la conciencia, hunde sus raíces en el fondo oscuro de la infancia, que ofrece una resistencia inexpugnable y de donde los recuerdos luchan por aparecer. Tomado en su conjunto, el poema ofrece un movimiento pendular entre la emoción de la primera infancia ("Soñé la galería / al huerto de ciprés y limonero") y la posibilidad de seguir gozando de su amor tardío en re lación con la atemporalidad del ciclo natural ("La augusta confianza / a ti, Naturaleza, y paz te pido, / mi tregua de terror y de esperanza, / un grano de alegría, un mar de olvido..."). Entre ambos extremos, la virtualidad del "Todavía", que es y sigue siendo. Esos versos desplazados, subrayados mediante los términos en mayúscula, la marca subjetiva de la exclamación y el encabalgamiento (“¡Oh Tiempo, oh Todavía / preñado de inminencias!"), constituyen el núcleo del poema, porque en ellos la fluidez de la vida-tiempo, simbolizada por "la saeta en el arco tenso", donde arquero y blanco dejan de ser dos objetos opuestos y se transmutan en realidad única, constituye un acto ritual de dimensión estética, que ha de relacionarse con la realidad última. Ante todo, se trata de armonizar, en el centro inmóvil del poema, lo que ha sido y lo que todavía no ha llegado a ser, pues el presente es como una flecha lanzada hacia lo desconocido, de expresar la virtualidad de lo posible, que es el lenguaje de la poesía, pues lo poético viene siempre del sentimiento de una inminencia8.

Estamos tejidos por el hilo del tiempo, por su ritmo eterno y fugaz. La grandeza poética de Machado es sentir que el ayer está siempre presente, que el emplazamiento de lo efímero sobre las ruinas del tiempo histórico tiene por objeto devolver al tiempo lo que era antes de convertirse en historia, cicatrizar una desgarradura. Los poemas que Machado escribe durante la guerra tienen todos ellos en común esa condición integradora de la frontera o el límite, espacio cambiante y humano en que conciencia y naufragio se confunden. Sus virtualidades de desgarramiento y de conflicto generan, desde su íntima contradicción, un impulso hacia el fondo primordial, hacia los orígenes del propio ser, pues la lejanía del recuerdo que subsiste, en tanto que ser vivo, no se extingue, sino que fluye y duele. Así, contra la desolación y angustia de la guerra, contra el desgarro de su "tajo fuerte", se levanta el retorno a la infancia originaria:

${ }^{8}$ Sobre el sentimiento de inminencia como naturaleza de lo poético, Cf. M. Ballestero, "Forma e inminencia", en Crítica y marginales, Barcelona (Barral Ed) 1974, pp.97-100. Respecto a la relación entre arco y flecha como apertura de una vía de iluminación, característica de la mística y la poesía, véase el clásico estudio de E. Herrigel, El Arte del Tiro con Arco, $6^{\mathrm{a}}$ ed., Buenos Aires (Kier) 1984. 
Otra vez el ayer. Tras la persiana, música y sol; en el jardín cercano, la fruta de oro, al levantar la mano, el puro azul dormido en la fontana.

5 Mi Sevilla infantil, ;tan sevillana!, ¡cuál muerde el tiempo tu memoria en vano!

¡Tan nuestra! Aviva tu recuerdo, hermano.

No sabemos de quién va a ser mañana.

Alguien vendió la piedra de los lares

10 al pesado teutón, al hambre mora,

y al ítalo las puertas de los mares.

¡Odio y miedo a la estirpe redentora

que muele el fruto de los olivares,

y ayuna y labra, y siembra y canta y llora!

Decir tiempo es decir destrucción, comprender el hecho mismo del tránsito en la interminable disgregación de cada instante, pues el tiempo está carcomido por dentro. Se ha dicho con frecuencia, a propósito de este poema, que la experiencia de la guerra no acaba de ajustarse al recuerdo del jardín infantil. Y, sin embargo, su fuerza constitutiva hay que buscarla precisamente en el tiempo edénico del jardín, estado de inocencia natural, cuya característica sería la contemplación, e imagen cierta del hombre no escindido. Si la evocación de los cuartetos se impone al énfasis declamatorio de los tercetos, es porque, bajo las preocupaciones de Machado en esos momentos, la traición a la patria, el honor escarnecido de los campesinos andaluces y el respeto al pueblo, late siempre ese lugar de la memoria, símbolo del escenario eterno. De ahí que los principales recursos expresivos, como la marca subjetiva de la exclamación ("icuál muerde el tiempo tu memoria en vano!"), que introduce el punto de vista del hablante; el apóstrofe del poeta a su hermano Manuel (vv.8-9), que está al otro lado, como llamada a la integración en una misma experiencia compartida; las marcas temporales de las formas verbales ("Otra vez el ayer", "No sabemos de quién va a ser mañana"), que oscilan entre la presencia del pasado y la indeterminación del futuro; y la serie de resonancias simbólicas ("el jardín cercano", "la fruta de oro", "Ia fontana"), que aluden al tiempo originario de la infancia, vayan todos ellos en función del reconocimiento de aquello que es esencial y permanente. En un momento de proximidad a la muerte, poseer el sentido de lo perpetuo, la sombra misteriosa del jardín infantil, equivale a instalarse en la tradición ("la estirpe redentora"), a superar lo histórico y hacerse intemporal 9 .

${ }^{9}$ El ámbito cerrado del jardín ("Paraíso cerrado para muchos, jardines abiertos para pocos", según el granadino Soto de Rojas), formaría parte de los espacios simbólicos machadianos, coincidentes en ser recintos cerrados, interiores. En este sentido del espacio cerrado, del espacio con el tiempo dentro ("galería - sueño - espejo - alma"), véase el estudio de R. Gullón, Espacios poéticos de Antonio Machado, Madrid (Fundación Juan March / Cátedra) 1987, pp.9-32. En cuanto a la interpretación del poema, hecha desde el punto de vista existencial y político más que poético, véase 
La creación artística es sucesión y gradación a lo largo del tiempo. En una obra poética como la de Machado, que ha ido creciendo al ritmo de la vida, los recursos expresivos no son siempre los mismos, si bien, al estar sostenidos por un tono íntimo, varían muy poco. Así pues, la cronología es la clave de la comprensión, pues sólo podemos juzgar al poeta si hemos leído cada uno de sus versos. Teniendo en cuenta esta prolongada convivencia con los poemas, observamos dos conceptos fundamentales en la estética machadiana: el contenido humano y el sentido temporal. En realidad, ambos son complementarios, pues el gran poeta habla de lo que ama y está dado de cuerpo entero en sus poemas. Además de esto, el poeta es al guien que ha salido de los confines del alma en la palabra, de modo que ésta es una creación temporal, que necesita de lo visible para elevarse a lo invisible. En la lírica de Machado, la idea de devenir sustituye a la de ser ("Ya nuestra vida es tiempo"), no presentándose la obra poética de una sola vez, sino en transcurso, con la fluidez misma del agua, ya que la palabra poética sólo se reconoce en su fluir. ¿No sería el agua, la imagen más transparente de la memoria, el símbolo primordial de la lírica machadiana? En Nuevas canciones, el poeta nos dice que la palabra poética es 'palabra en el tiempo', palabra que fluye, como la vida misma, añadiendo en su transcurrir nuevos significados. Esa idea de viaje entre el origen conocido y el misterioso futuro está presente en los versos de "Poema de un día", que así aparece como centro de toda su poesía:

¡Oh tú, que vas gota a gota,
fuente a fuente y río a río,
como ese tiempo de hastío
corriendo a la mar remota,
con cuanto quiere nacer,
cuanto espera
florecer
al sol de la primavera,

¡Oh tú, que vas gota a gota, fuente a fuente y río a río, como ese tiempo de hastio corriendo a la mar remota, cuanto espera florecer al sol de la primavera,

\author{
sé piadosa, \\ que mañana \\ serás espiga temprana, \\ prado verde, carne rosa, \\ y más: razón y locura \\ y amargura \\ de querer y no poder \\ creer, creer y creer!
}

El hecho de que estos versos vayan rodeados por la marca subjetiva de la exclamación les confiere un tono íntimo, contradictorio, como la vida misma, llena de 'razón y locura'. Antonio Machado, igual que Santa Teresa y San Juan de la Cruz, fue visitado por el sueño de las aguas oscuras, que es gestación de un nuevo alumbramiento, siendo ese sueño de los orígenes el que arrastra la memoria, que aparece siempre como viniendo de un olvido. Remontar las aguas del recuerdo es ir hacia el dominio sobre el tiempo, ingresar en la indeterminación de lo poético, como si toda forma resultara, en su seno, más flexible y sutil. La voz más genuina de Machado, en sus varias manifestaciones, la voz lírica de Soledades, la histórica de Campos de Castilla y la más filosófica de Nuevas canciones,

el análisis de A. Sánchez Barbudo, Los poemas de Antonio Machado, $4^{\mathrm{a}}$ ed., Barcelona (Lumen) 1981, pp.463-465. 
es siempre una voz esencial, que retiene pocas cosas, pero de forma duradera. Con esa voz honda y delgada, que trata de buscar aquello que es permanente y nos remite a una mayor austeridad, Machado ha entrado por derecho propio en lo mejor de nuestra tradición. Así prosigue su escritura, simple e irremplazable, en un continuo prestar oído, como si su melodía hubiera sido dada desde el principio y el lector sólo estuviera reconstruyéndola a cada instante ${ }^{10}$.

${ }^{10}$ Sobre la concepción del tiempo artístico, tiempo interno que genera el florecimiento de sus formas, Cf. J. Camón Aznar, El tiempo en el arte, $2^{\mathrm{a}}$ ed., Madrid (Organización Sala Editorial) 1972. Para la integración de humanismo y temporalidad en la lírica de Machado, ver A. Masoliver, “Antonio Machado: las voces traicionadas", Cuadernos Hispanoamericanos 583, pp.63-70; y 585, pp.79-89. 